\title{
Práticas agroecológicas em assentamentos rurais no sul do Amazonas: uma abordagem institucional
}

\section{Agroecological practices in rural settlements in southern Amazonas: an institutional approach}

Francimara Souza da Costa - Doutora em Ciências Socioambientais (NAEA/UFPA). Professora Adjunta da Universidade Federal do Amazonas (UFAM), Manaus-AM. E-mail: francimaracosta@ yahoo.com.bre francimara@ufam.edu.br

Nirvia Ravena - Doutora em Ciência Política. Professora Adjunta da Universidade Federal do Pará (UFPA). Núcleo de Altos Estudos Amazônicos, Belém-PA. E-mail: niravena@gmail.com

\section{Resumo}

Este artigo apresenta uma discussão em torno das formas de acesso e uso dos recursos naturais em assentamentos rurais "sustentáveis" no Amazonas, relacionando -as aos postulados da política de reforma agrária. O estudo foi realizado por meio de análise comparativa a partir do método Institutional Analysis and Development (IAD) Framework. Os resultados apontam que as dificuldades apresentadas em torno da organização social e as relações institucionais enfraquecidas culminam na vulnerabilidade da permanência das práticas agroecológicas nos assentamentos. Entretanto, em meio a esta instabilidade, os moradores atuam a partir de escolhas que lhes propocionam a continuidade de inovações tecnológicas de base agroecológica, criadas mediante as necessidades das famílias e sua experimentação empírica.

\section{Palavras-chave}

Práticas agroecológicas. Assentamentos rurais. Instituições.

\begin{abstract}
This article presents a discussion on the forms of access and use of natural resources 'sustainable' rural settlements in the Amazon, relating them to the principles of agrarian reform policy. The study was conducted by means of comparative analysis from the Institutional Analysis and Development (IAD) Framework method. The results indicate that the difficulties presented around the social organization and weakened institutional relations culminate in the vulnerability of the permanence of agroecological practices in the settlements. However, in the midst of this instability, the residents work from choices that provide them the continuity of technological innovations agroecological base, created by the needs of families and their empirical experimentation.
\end{abstract}

\section{Keywords}

Agroecological practices. Rural settlements. Institutions. 


\section{INTRODUÇÃO}

A implantação de assentamentos rurais destinados ao uso sustentável no Estado do Amazonas, tomados como modelo de regularização fundiária para a região pela Política Nacional de Reforma Agrária (PNRA), é apresentada como alternativa para o enfrentamento dos problemas característicos das populações rurais e tradicionais locais. Entretanto, em algumas áreas rurais do Amazonas estes assentamentos transformaram-se em um problema tão grave quanto a falta de regularização, pois a deficiência na infraestrutura do órgão gestor para acompanhamento das atividades e a imposição de regras pouco adequadas à realidade dos moradores têm agravado conflitos socioambientais já existentes e pouco têm contribuído para avanços relacionados às melhorias dos sistemas de uso dos recursos naturais.

Este artigo objetiva apresentar uma discussão em torno das formas de acesso e uso dos recursos naturais desenvolvidas por moradores de assentamentos rurais "sustentáveis", localizados no município de Humaitá, região sul do estado do Amazonas, relacionando suas práticas de uso aos postulados da política de reforma agrária. A análise buscou verificar a influência desta política na manutenção, limitação ou melhoria das práticas produtivas e reprodutivas desenvolvidas pelos moradores que contribuem para a conservação dos recursos naturais, enfocando-se as práticas características dos princípios da agroecologia.

A região sul do Amazonas constitui um cenário propício para estudar os efeitos de intervenções governamentais sobre o uso de recursos comuns. A região é considerada estratégica para a articulação de ações de desenvolvimento do Estado, como o fortalecimento das cadeias de comercialização, em função da sua localização, com acesso tanto por via fluvial como através das rodovias BR-319 e BR-230 (Transamazônica) que ligam o Estado ao restante do país. A região pertence ao denominado "Complexo Madeira", reconhecido como eixo de ligação na Pan-Amazônia, e é alvo de intensas transformações econômicas e sociais promovidas por políticas governamentais impostas principalmente àqueles que dependem do uso dos recursos naturais para viver. As ações mostram-se muitas vezes controversas, pois ao tempo em que as políticas ambientais criam amplos corredores ecológicos de proteção, buscando conservar os recursos naturais e incentivar o desenvolvimento de atividades sustentáveis, há, por outro lado, incentivo governamental para implantação de corredores de desenvolvimento com foco no crescimento econômico, como implantação de barragens, hidrelétricas, madeireiras, representados principalmente pelo Programa 
de Aceleração do Crescimento (PAC), Plano Decenal de Energia (PDE), Plano Amazônia Sustentável (PAS) e Plano Nacional de Recursos Hídricos.

Apesar dos efeitos negativos de alguns processos de intervenção governamental sofridos pelos povos que habitam as áreas rurais e utilizam os recursos naturais como meio de vida, observa-se uma capacidade transformadora destes atores, evidenciada pela reformulação das formas organizativas, produtivas e fortalecimento das identidades coletivas (ALMEIDA, 2009). Constituídas por populações tradicionais ou migrantes vindos de outras regiões do Brasil, as comunidades organizam-se de forma autônoma e lutam pelo direito à terra, aos recursos hídricos, à proteção dos castanhais e ao uso dos recursos naturais privatizados, algumas vezes de forma ilegal (ALMEIDA, 2009).

Este estudo reconhece as práticas agroecológicas realizadas pelos moradores dos assentamentos como estratégia de produção e reprodução social. Construídas e reformuladas ao longo de gerações, estas práticas representam a capacidade de adaptação e superação dessas populações mediante as dificuldades impostas pelas características geográficas da região (tais como longas distâncias das comunidades aos centros urbanos, péssimas condições de transporte e de tráfego) e as intempéries ambientais, marcadas principalmente pelos períodos de cheia e seca do rio Madeira.

Desta forma, a análise permeia a identificação das práticas produtivas realizadas nos assentamentos, associando-as ao desenho institucional direcionado à gestão dessas Unidades, destacando-se suas potencialidades e vulnerabilidades. Além disso, a pesquisa apresenta as práticas agroecológicas utilizadas pelos moradores da região, contribuindo para fundamentar cientificamente a reprodução de sistemas produtivos agroecológicos de forma adequada à realidade amazônica.

\section{METODOLOGIA DA PESQUISA}

O estudo foi realizado por meio de análise comparativa entre o Projeto de Assentamento Agroextrativista (PAE) Botos e o Projeto de Desenvolvimento Sustentável (PDS) Realidade, assentamentos rurais caracterizados como "sustentáveis" pelo Instituto Nacional de Colonização e Reforma Agrária (INCRA). Os assentamentos estão localizados no município de Humaitá, região sul do Amazonas.

A Comparação entre as Unidades foi ordenada a partir do método Institutional Analysis and Development (IAD) Framework criado por Elinor Ostrom (OSTROM et al., 1994) para análise de Common-Pool Resource (OSTROM, 1990). O IAD Framework de Ostrom tem como unidade de análise a arena de ação, cujo 
desenho é apresentado pela identificação dos atores envolvidos e das relações institucionais existentes nos processos de decisão relativos ao uso de recursos comuns. Os resultados do Framework são apresentados a partir de critérios de avaliação previamente definidos, analisando-se a arena de ação segundo a influência de variáveis externas (condições biofísicas e materiais, cultura e regras de uso) e dos processos de interação entre os atores.

Neste estudo, O IAD Framework de Ostrom foi adaptado conforme apresenta a Figura 1. A variável externa considerada como influenciadora e influenciável pela arena de ação é o arranjo institucional existente em torno do uso dos recursos naturais e o critério de avaliação é a forma como estes arranjos refletem sobre as práticas agroecológicas desenvolvidas pelos moradores.

Figura 1: Quadro lógico para análise da arena de ação.



Fonte: Adaptado do IAD Framework de Ostrom (2005).

A arena de ação apresentada na Figura 01 é ainda avaliada por meio de comparação entre as Unidades. Para Schneider e Schmitt (1998), a comparação permite descobrir fatores de regularidades, reconhecer mudanças, construir modelos e tipificações, identificar continuidades e transformações e explicar determinadas variáveis que imperam em fenômenos sociais. Para os autores, o método comparativo é um elemento racional de controle, cujos resultados interpretativos permitem estabelecer relações de causa-efeito, permitindo uma visão ampla e detalhada dos fenômenos estudados.

As informações da pesquisa foram coletadas a partir de dados quantitativos e qualitativos de fontes primárias e secundárias. Os dados secundários foram 
coletados em fontes bibliográficas e documentais de instituições governamentais e não governamentais (INCRA, ICMBio, Associações, Cooperativas e outros). Os dados primários foram coletados por meio da aplicação de formulários estruturados junto aos chefes de família, além da observação direta, conversas informais com os moradores das Unidades e coleta de informações em reuniões com as comunidades.

Foram entrevistados 30\% dos domicílios de cada Unidade e o(a) informante era o(a) chefe de família. As questões dos formulários referiam-se a informações relacionadas às práticas agroecológicas desenvolvidas nas Unidades e suas percepções a respeito das instituições formais e informais envolvidas nos processos produtivos. Durante a entrevista, foi dado espaço para expressão de percepções pessoais do(a) entrevistado(a) a respeito dos temas questionados. Quando havia mais de uma família por domicílio, apenas o(a) chefe mais velho(a) foi entrevistado(a).

A coleta de dados ocorreu entre julho de 2011 e julho 2013. As viagens às comunidades e a aplicação dos formulários foram viabilizadas conjuntamente com ações desenvolvidas pelo Núcleo de Pesquisa e Extensão em Ambiente, Socioeconomia e Agroecologia (NUPEAS) da Universidade Federal do Amazonas (UFAM), localizado no Instituto e Educação, Agricultura e Ambiente (IEAA), campi da UFAM no município de Humaitá e pelo Núcleo de Socioeconomia (NUSEC) da UFAM, localizado na sede de Manaus. A aplicação dos formulários contou com o auxílio e colaboração de alunos de graduação e pesquisadores vinculados aos Núcleos.

No NUPEAS, o estudo foi vinculado ao projeto "Desenvolvimento de Tecnologias Sociais e Agoecológicas em comunidades rurais do Sul do Amazonas", financiado pelo Ministério do Desenvolvimento Agrário (MDA) em parceria com o Conselho Nacional de Desenvolvimento Científico e Tecnológico - CNPq, onde foram coletadas as informações referentes ao PAE Botos. No NUSEC, a coleta de informações ocorreu em conjunto com as ações do projeto "Programa de Implantação das Unidades de Conservação na área de Influência da BR-319 no Estado do Amazonas", financiado pelo Departamento Nacional de Infraestrutura e Transporte (DNIT) e executado pelo NUSEC, em parceria com a Fundação Rio Solimões (UNISOL) e Centro Estadual de Unidades de Conservação do Amazonas (CEUC), onde foram coletadas as informações do PDS Realidade. 


\section{CARACTERIZAÇÃO ESPACIAL E DEMOGRÁFICA DA ÁREA DE ESTUDO}

As Unidades analisadas neste trabalho estão localizadas no município de Humaitá, situado na mesorregião do sul amazonense e na microrregião do Rio Madeira. Humaitá possui uma área de $33.072,00 \mathrm{~km}^{2}$ e sua população é de 44.227 habitantes. A economia é baseada na pecuária de bovinos, pesca, agricultura de arroz e hortaliças, movelaria, extrativismo de castanha e açaí, e garimpo (IBGE, 2010). O ordenamento territorial de Humaitá constitui-se basicamente de assentamentos de reforma agrária, Unidades de Conservação e terras indígenas, conforme apresenta a Figura 2.

Figura 2: Ordenamento territorial do município de Humaitá.

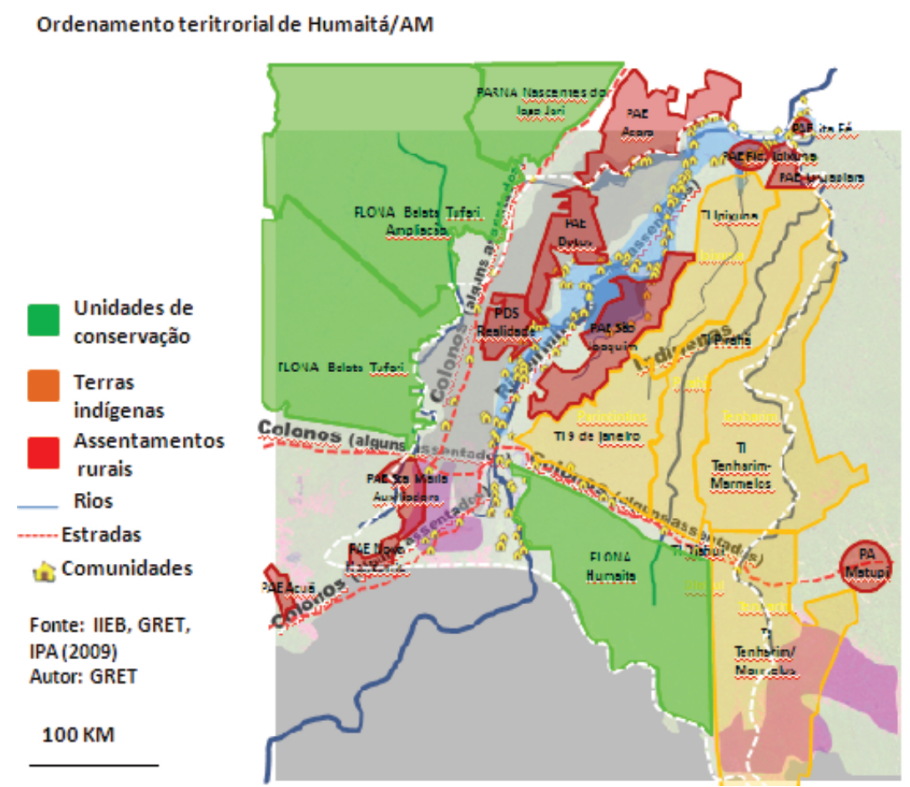

Fonte: IIEB, GRET, IPA (2009).

O PAE Botos foi criado em 2004 e possui uma área de 101.394 ha. É composto de três comunidades (Botos, Pirapitinga e Escapole) com aproximadamente 58 famílias, possuindo capacidade para 200 famílias (BRASIL, 2011). As principais atividades produtivas desenvolvidas no assentamento são o extrativismo de castanha e açaí, pesca, e mandioca para produção de farinha.

As discussões para criação do PAE Botos surgiram no final de 1991, a partir de um funcionário do INCRA que em conversa com as lideranças locais informou a existência de terras pertencentes à União, passíveis de destinação 
para reforma agrária, o que poderia assegurar posse e uso dos recursos florestais pelos moradores locais (IIEB, 2008). A conversa estimulou a associação dos moradores da área, denominada Associação dos Moradores do Muanense a solicitar do INCRA de Humaitá a criação do assentamento.

Somente em 2004 foi aprovada a criação do assentamento por meio da Portaria 08/2004-INCRA. No processo de demarcação das áreas de ocupação e uso dos recursos, algumas localidades foram reivindicadas por proprietários munidos de documentação datada de 1930, época concernente à tomada de posse dos seringais da região. As propriedades foram reconhecidas pelo INCRA como áreas tituladas e os "donos das terras" praticamente indicaram qual seria a área destinada ao assentamento, tendo as famílias moradoras da área baixa participação neste processo. Este fato culminou na exclusão de parte das famílias e das áreas de uso destas do perímetro do assentamento, o que catalisou conflitos entre assentados e proprietários, principalmente relacionados às áreas dos roçados e de coleta de castanha-do-brasil. Os donos de terra exigem parte da produção dos assentados e intimidam os moradores até mesmo com uso de violência (IIEB, 2008).

Como parte da área de uso das famílias não estão incluídas no perímetro do assentamento, para terem acesso aos benefícios, os moradores necessitam se deslocar dos locais onde moram e realizam o extrativismo, o que representa uma dualidade: para terem acesso ao Programa de Reforma Agrária são obrigados a declinar dos direitos fundiários sobre as áreas tradicionalmente ocupadas. Considerando que uma das finalidades deste Programa é a modificação do regime de posse e direito de uso da terra, configurado pelas relações de poder e mando entre "patrões" e "fregueses" estabelecidos há décadas na região, no PAE Botos estas relações permanecem inalteradas (IIEB, 2010).

Em relação ao PDS Realidade, este foi criado em 2007 e possui área de 43.773,4051 ha. É constituído de duas comunidades e cerca de 165 famílias, entretanto, a capacidade do assentamento informada pelo INCRA é de 250 famílias. Está instalado no km 100 da BR-319 (Manaus-Porto Velho) e tem sua dinâmica econômica e social associada à influência da rodovia. Ao contrário do PAE Botos, que é constituído de comunidades tradicionais ${ }^{1}$, as comunidades do PDS Realidade são formadas principalmente por migrantes vindos das regiões Sul e Centro-Oeste do Brasil (BELLO; COSTA, 2011).

\footnotetext{
O Decreto 6.040, de 7 de fevereiro de 2007, conceitua povos e comunidades tradicionais no artigo $3^{\circ}$, inciso I, como "grupos culturalmente diferenciados e que se reconhecem como tais, que possuem formas próprias de organização social, que ocupam e usam territórios e recursos naturais como condição para sua reprodução cultural, social, religiosa, ancestral e econômica, utilizando conhecimentos, inovações e práticas gerados e transmitidos pela tradição".
} 
Construída na década de 1970, a BR-319 trouxe um grande contingente de migrantes para região, que vieram estimulados pela facilidade de aquisição de terras e possibilidades de desenvolvimento local, pois o governo iniciou na época uma série de incentivos para o plantio de grãos e exploração agropecuária, objetivando a incorporação das terras do entorno da rodovia ao mercado de commodities (FLECK, 2009). Porém, atualmente, o trecho correspondente ao PDS Realidade está intransitável desde 1986. Acredita-se que as dificuldades de acesso ao local trouxeram importantes reconfigurações socioeconômicas, pois os moradores foram obrigados a adaptar novas formas de organização social e produtiva para a sua permanência.

Após o aparecimento de possibilidades recentes da reconstrução da BR-319 (FLECK, 2009), o simples anúncio da repavimentação da rodovia tem estimulado novas famílias a se instalarem no local. Desta forma, os moradores demandaram do INCRA a criação do assentamento, no intuito de obter o documento de propriedade e impedir a invasão e a posse de terras por novos moradores.

A criação do PDS Realidade demonstra mais uma incongruência da política de reforma agrária no Brasil e a realidade vivenciada em cada região, especialmente relacionada às demandas da população. Ao solicitar a criação do assentamento ao INCRA, os moradores objetivavam a definição dos lotes e o recebimento do documento de propriedade. Entretanto, a modalidade PDS não permite a demarcação de propriedades individuais, tendo os moradores que se adaptar ao "uso comum". Este fato também tem culminado em conflitos no local, seja pelo desconhecimento dos moradores em relação aos critérios de uso dos recursos da área, ou seja, sobre o desenho institucional do uso comum na política ou, ainda, pela falta de orientação do INCRA na apropriação dos moradores a esta nova realidade.

Assim, a comparação entre as Unidades permitiu a observação de como realidades diferenciadas no tocante às características de conformação das comunidades e de suas formas de acesso e uso dos recursos, apresentam resultados semelhantes quando são considerados os efeitos dos desenhos institucionais estabelecidos na implantação dos assentamentos. O Estado, que deveria mediar e solucionar os conflitos existentes em torno do direito ao uso dos recursos, muitas vezes manifesta-se como acirrador dos desentendimentos e da insatisfação dos moradores em relação às políticas regulatórias do uso de recursos comuns nas áreas rurais amazônicas. 


\section{ASPECTOS DA ANÁLISE INSTITUCIONAL}

Instituições são aqui compreendidas como organizações ou dispositivos sociais que regulam o funcionamento da sociedade e, portanto, dos indivíduos, a partir de regras, valores, normas e suas respectivas mudanças, estabelecidas e reconhecidas coletivamente (OSTROM, 1990 HODGSON,2006).

Para Bresser-Pereira (2004), a origem das instituições pode ser explicada pelo surgimento do Estado-nação. Ao examinar a origem do Estado a partir das teorias histórica, normativa e contratualista, o autor apresenta-o como instituição soberana, matriz de todas as instituições formais. O Estado é a instituição que ordena a sociedade por meio da Constituição nacional e respectivos instrumentos legais que o legitimam. É, portanto, o mecanismo regulador da ação coletiva, por meio do qual os objetivos políticos de ordem ou estabilidade social, liberdade, bem-estar e justiça social buscam ser alcançados.

As instituições são então estruturas executoras das ações planejadas pelo Estado para ordenar a ação coletiva. Para tanto, a efetividade institucional depende de sua adequação ao sistema social e econômico ao qual estão inseridas e sua adaptação aos aspectos culturais (valores e crenças) da sociedade correspondente. Como instrumento de desenvolvimento, compõe um sistema complexo, em que a preocupação única com as propriedades e contratos pode ser um entrave ao desempenho do seu papel, evitando assim a visão reducionista do novo institucionalismo (BRESSER-PEREIRA, 2004).

As instituições sempre foram arranjos que diminuíram os custos de transação entre os indivíduos. Para os jusnaturalistas como Hobbes, Locke e Rousseau, eram os elementos que possibilitavam o contrato social onde regras, crenças e valores eram arregimentados para dar substância procedimental ao que era pactuado (REPLOGLE, 1989; RAWLS, 2000)

A análise institucional permite a identificação dos elementos e atoreschave nos processos sociais e econômicos e sua importância intrínseca está na capacidade de atuar como reguladora da ação coletiva. Mancur Olson (1999), estudioso deste tema, em uma abordagem econômica, explica no livro a "Lógica da Ação Coletiva", como indivíduos atuam quando inseridos em organizações. Para o autor, um indivíduo age coletivamente impulsionado por interesses individuais, ainda que partilhe dos mesmos interesses do grupo, como a maximização do lucro, por exemplo. Portanto, para que o indivíduo seja inserido em determinado grupo e passe a agir em função de interesses comuns, é necessária uma força externa de coerção que o impulsione, aparecendo aí o papel das instituições. 
As instituições possuem, desta forma, segundo Olson, um importante papel na promoção de interesses comuns em grupos. Cabe às organizações, portanto, prover benefícios ao indivíduo (não coletivos) que o estimule a aderir ao grupo (OLSON, 1999) - e aqui entra a função do Estado. No entanto, embora os membros do grupo partilhem do mesmo objetivo coletivo a ser alcançado por intermédio da instituição, nem todos os membros estão dispostos a pagar os custos de forma coletiva, já que preferem que os demais membros paguem sozinhos. Assim, comparando as ações de grandes e pequenos grupos, Olson conclui que grupos pequenos conseguem controlar de forma mais eficiente os custos individuais, sendo inclusive desnecessária uma força coercitiva para o alcance dos interesses comuns. Já em grandes grupos, este controle é dificultado e o grupo acaba impossibilitado de atingir o nível ótimo do benefício coletivo (OLSON, 1999).

A adoção do Institutional Analysis and Development (IAD), portanto, permite a análise da interação dos elementos sociais, culturais e ambientais presentes na arena que caracteriza o uso de recursos comuns na Amazônia, e em particular, em áreas de reserva e assentamentos agroextrativistas. Os dilemas de ação coletiva associados ao desenvolvimento social e cultural de estratégias para a não ocorrência do esgotamento dos recursos naturais, associados às regras que derivam dessas estratégias, podem ser identificadas através desse framework.

Além da dinâmica interna dos grupos sociais que vivem nas Reservas e Assentamentos em áreas amazônicas, a análise também adota a perspectiva institucional para compreender a dinâmica das políticas públicas nessas comunidades. A teoria institucional, portanto, operacionaliza a identificação das formas de interação entre aqueles que desenvolvem arranjos institucionais para o uso comum de recursos naturais e o desdobramento das ações do Estado sobre esses arranjos.

Assim, numa perspectiva sumarizada, a abordagem aqui proposta utilizou a análise institucional para compreender a dinâmica do uso dos recursos naturais nos assentamentos rurais estudados, considerando a ação coletiva que coaduna na conservação dos recursos e se manifesta nas práticas agroecológicas. Além disso, foi observado o papel da PNRA, por meio das relações dos moradores com as instituições governamentais envolvidas, na organização ou reorganização das regras que norteiam estas práticas. 


\section{ASSENTAMENTOS RURAIS COMO MEDIADORES INSTITUCIO- NAIS DO USO DOS RECURSOS NATURAIS}

A "tragédia dos comuns" de Garret Hardin (1968) e a noção da "imprescindível" necessidade da ação do Estado para evitar a destruição dos recursos naturais não renováveis, suscitou a ideia de delimitar áreas como instrumento para conservação da biodiversidade e minimização dos efeitos das atividades antrópicas sobre a natureza. A primeira área protegida criada foi o Parque Nacional de Yellowstone, no final do século XIX, nos Estados Unidos. Nesta área foi proibida a permanência de moradores, tendo sido criada numa perspectiva preservacionista, onde as espécies vegetais e animais deveriam permanecer intocadas. Este modelo americano de preservação da natureza espalhou-se pelo mundo, e no Brasil necessitou ser reformulado, devido à presença de grande número de pessoas que moram em áreas de florestas e utilizam os recursos naturais para sua sobrevivência. O modelo da "natureza intocável" deixou de considerar os diferentes modos de vida das populações ditas tradicionais, que nem sempre se relacionam de forma nociva com o meio ambiente, pois utilizam estratégias de manutenção dos recursos, já que deles depende o seu modo de vida (DIEGUES, 2002).

Com a diversidade das relações existentes entre grupos humanos e natureza, houve necessidade do estabelecimento de conceitos e diretrizes que abrangessem de modo geral as necessidades de ambos a nível mundial. A realização de encontros entre representantes de diversos países para debater a temática possibilitou modificações conceituais para a criação de áreas protegidas. Além do modelo clássico, que proíbe a permanência de moradores na área, foram também instituídas modalidades que permitem a convivência entre grupos humanos e floresta, que possibilitem a conservação dos recursos naturais e a manutenção do modo de vida dessas populações.

A partir daí, os principais instrumentos legais instituídos na tentativa de conciliar a conservação da natureza com o modo de vida das populações tradicionais foi o código florestal e o Sistema Nacional de Unidades de Conservação da Natureza (SNUC). O código florestal estabelece limites para o tamanho da área de uso das propriedades, garantindo a manutenção de uma parcela da vegetação natural. O SNUC resultou no investimento do governo federal a partir do ano 2000, na definição de áreas prioritárias de conservação para implementação de Unidades de Conservação (UCs), destacando-se na região estudada o Programa Áreas Protegidas da Amazônia (ARPA) e o Projeto Corredores Ecológicos. O Projeto Corredores Ecológicos foi proposto em 
1997 e tem como objetivo principal conservar a biodiversidade a partir de parcerias com todos os atores sociais envolvidos e demais instituições do setor. Já o Programa ARPA, foi iniciado em 2000, e possui metas mais quantitativas quando comparado ao Projeto Corredores, objetivando principalmente proteger aproximadamente 50 milhões de hectares de florestas, a partir da implantação de Unidades de Conservação.

Tomando o gancho deste cenário, o Plano Nacional de Reforma Agrária incluiu a previsão da criação de assentamentos rurais, chamados ambientalmente diferenciados ou assentamentos sustentáveis, incorporando a ideia de gestão participativa destes espaços, a ser realizada em conjunto com as organizações sociais estabelecidas pelas comunidades. Fazem parte deste grupo de assentamentos o Projeto de Assentamento Agroextrativista (PAE), criado em 1996, destinado à exploração de áreas ricas em recursos extrativistas; o Projeto de Desenvolvimento Sustentável (PDS), criado em 1999, destinado às populações que têm o extrativismo e a agricultura familiar como base de vida; e o Projeto de Assentamento Florestal (PAF), criado em 2006, destinado a áreas com aptidão para o manejo florestal de uso múltiplo. As atividades desenvolvidas nestas áreas devem ser de base familiar, executadas coletivamente e obrigatoriamente devem ser economicamente viáveis e ecologicamente sustentáveis (BRASIL, 2010).

Um dos objetivos da criação destes assentamentos, preconizado na política agrária, é estimular os processos de organização comunitária e de uso comum dos recursos naturais, estabelecendo-se como instrumentos que garantem a posse e o uso dos recursos pelos assentados, a Concessão do Direito Real de Uso (CDRU) e o Plano de Uso (PU) do assentamento. O CDRU teoricamente deveria garantir ao titular a realização de atividades compatíveis com a legislação, para atender as necessidades das famílias (BRASIL, 2010). O PU é um documento formal elaborado pelos moradores e aprovado pelo INCRA, que regulamenta as regras de utilização dos recursos da área.

Os assentamentos analisados neste estudo ainda não possuem o PU elaborado, mesmo tendo o PAE Botos dez anos de criação (2004) e o PDS Realidade, sete anos (2007). Este fato retrata a limitação do órgão gestor (INCRA) para implementação da política, uma vez que não conseguiu ainda auxiliar os moradores na elaboração do planejamento comunitário e na formulação ou adequação das regras de uso.

A regularização fundiária mediante a criação dos assentamentos sustentáveis esbarra em vários entraves na região. Dentre eles, a morosidade do processo de concessão do direito de uso, que muitas vezes ao invés de solucionar os conflitos de propriedade e uso, agrava ainda mais aqueles anteriormente 
existentes, já que os direitos reconhecidos informalmente pelos moradores são modificados e a demora do INCRA para esclarecimento e adequação das novas regras às realidades de cada assentamento contribui, muitas vezes, para acirrar os desentendimentos entre moradores e entre moradores e usuários externos.

Além disso, a insuficiência de apoio do órgão gestor para fortalecimento da organização social, tanto para estruturação do Plano de Uso quanto para acompanhamento no desenvolvimento dos programas (quando existem), limita a gestão participativa, ou simplesmente contribui para permanência da inexistência da gestão comunitária. Se os moradores não são apropriados de conhecimento da legislação e de seus direitos e deveres enquanto assentados desta categoria de uso comum, dificilmente é suscitado o processo de participação comunitária e da organização de atividades coletivas.

\section{A INSTITUCIONALIZAÇÃO DA PRODUÇÃO AGROECOLÓGICA}

Um dos objetivos da implantação de assentamentos rurais sustentáveis na Amazônia é a implantação de sistemas de uso dos recursos naturais com baixo impacto ambiental, que garanta o atendimento das necessidades básicas das famílias, tais como alimentação, moradia e renda. Estes sistemas podem ser inseridos no contexto dos princípios de sistemas agroecológicos de produção.

A agroecologia é uma nova abordagem da agricultura que procura integrar os aspectos agronômicos, ecológicos e socioeconômicos na produção de alimentos. Tem como objetivo primordial o uso racional dos recursos naturais, além da produção de alimentos mais saudáveis, com vistas ao aumento da segurança alimentar. A evolução para essa perspectiva de produção iniciou a partir da preocupação com a qualidade dos alimentos, pelo uso excessivo de produtos fitossanitários (agrotóxicos), sementes geneticamente modificadas e os danos ambientais ocasionados pelo uso de maquinário pesado e adubação química, práticas utilizadas pela agricultura convencional. Neste cenário, iniciaram-se as organizações para retomar as formas tradicionais de produção, como a agricultura natural no Japão, a agricultura regenerativa na França e a agricultura biológica nos Estados Unidos, além das formas que já existiam, a agricultura biodinâmica na Áustria e a agricultura orgânica na Inglaterra (CAPORAL; COSTABEBER, 2004).

Inicialmente os movimentos foram chamados de agricultura orgânica. Durante a década de 1990 foi incorporada uma visão mais integrada da produção agrícola, ressaltando-se a importância também de seu valor social, quando então o conceito passou a ser chamado de Agroecologia. Oficialmente, a 
agroecologia foi impulsionada pela Agenda 21, construída na Conferência para o Desenvolvimento e Meio Ambiente, realizada no Rio de Janeiro em 1992, evento conhecido como ECO 92. Na ocasião, foram criadas diretrizes para um desenvolvimento embasado em práticas sustentáveis de produção e daí em diante, técnicas alternativas de produção agrícola foram estimuladas e a procura por produtos orgânicos tem sido crescente no mercado.

Desde então, estas práticas têm sido incentivadas pelas políticas públicas, diante do avanço da produção agrícola em larga escala, impulsionada pela utilização da prática convencional na agricultura. O estímulo ao desenvolvimento de uma agricultura "conservacionista e ecológica" tem como princípios a utilização de métodos e técnicas que respeitem os limites do meio ambiente, tais como a policultura, o consorciamento e a rotatividade de espécies, com pouca ou nenhuma dependência de fertilizantes químicos e produtos fitossanitários, substituídos por adubo orgânico, compostagem, repelente natural e troca entre saberes científicos e saberes locais adquiridos pelos agricultores (CAPORAL; COSTABEBER, 2004).

As práticas agroecológicas são contrárias às práticas convencionais de produção. Nestas últimas, o objetivo principal é o aumento da produtividade, possibilitado pela intensa utilização de insumos externos (mecanização, fertilizantes químicos, produtos fitossanitários). Em curto prazo, o uso de insumos "modernos" traz um importante incremento no resultado econômico, porém, em longo prazo, provoca graves danos ambientais e gera a crescente necessidade de investimentos financeiros. Além disto, este sistema é baseado na monocultura de larga escala, o que pode gerar uma diminuição da diversidade genética (SOUZA, 2005).

Para ampliar a incorporação da agroecologia como forma de produção, o governo brasileiro instituiu, por meio do Decreto 7.794, de 20 de agosto de 2012, a Política Nacional de Agroecologia e Produção Orgânica (PNAP), com o objetivo de

Integrar, articular e adequar políticas, programas e ações indutoras da transição agroecológica e da produção orgânica e de base agroecológica, contribuindo para o desenvolvimento sustentável e a qualidade de vida da população, por meio do uso sustentável dos recursos naturais e da oferta e consumo de alimentos saudáveis".

A política prevê o apoio ao desenvolvimento de pesquisas, capacitação e assistência técnica, políticas específicas para financiamento, seguro, preços mínimos e compras governamentais, além de sistemas de monitoramento e avaliação da produção agroecológica. 
Desta forma, são apresentadas aqui as práticas agroecológicas utilizadas na região, reconhecendo estas como estratégias tecnológicas criadas e adaptadas pelos moradores em substituição às práticas convencionais de produção. Mediante a indicação nas políticas agrárias e ambientais da necessidade do desenvolvimento de sistemas sustentáveis de produção, parte-se da ideia que as práticas agroecológicas podem ser incorporadas aos programas governamentais destinados à região e, assim, analisa-se o papel das instituições governamentais no incentivo ou limitação do desenvolvimento de práticas baseadas nos princípios da agroecologia.

\section{O IAD FRAMEWORK DAS PRÁTICAS AGROECOLÓGICAS}

De modo geral, a produção agrícola das áreas estudadas é organizada de forma tradicional, com a utilização do fogo no preparo do solo para a implantação dos roçados. Após o plantio, a manutenção do roçado é realizada por meio de capina manual ou desbastes ${ }^{2}$. No PAE Botos, porém, não foram identificadas práticas de manutenção dos cultivos. $\mathrm{O}$ roçado não recebe tratos culturais e o agricultor retorna à roça somente para a realização da colheita.

Adams (2000) afirma que o fogo desempenha um papel fundamental na agricultura familiar, e a sustentabilidade deste sistema é evidenciada pela importância para a ciclagem dos nutrientes. Os nutrientes minerais existentes na biomassa florestal são mobilizados durante a queima e disponibilizados para as plantas na forma de cinzas. Porém, devido aos efeitos negativos causados pelo uso contínuo do fogo no preparo da área para o plantio, uma vez que reduz a fertilidade do solo pela perda de nutrientes, Alves e Modesto Júnior (2012) indicam o corte e trituração da capoeira como alternativa, o que evita a perda da fertilidade do solo, pois facilita a regulação do calor na superfície e a conservação da água, além de minimizar o trabalho no preparo de novas áreas.

Para manter a capacidade de produção do solo nestes ambientes, os agricultores utilizam o sistema de pousio, consistindo em deixar o solo "descansar" por um período de 2 a 3 anos para regeneração dos nutrientes (BOSEURUP, 1987; RAVENA, 2010; FRAXE, 2011). Branco (1993) reconhece dois tipos de sistemas de pousio realizados na Amazônia. O primeiro, chamado de pousio arbustivo on tradicional, consiste no abandono de uma área inicialmente utilizada para roça, por dois ou três anos, visando o desenvolvimento de capoeira (floresta

2 A capina manual e os desbastes consistem na retirada de plantas invasoras que prejudicam a produtividade dos cultivos.

Novos Cadernos NAEA • v. 17 n. 1 • p. 99-124 • jun. 2014 
secundária). E o segundo é chamado de pousio melhorado, quando a terra deixa de ser utilizada por um período para roça mas é incrementada com plantios de frutíferas.

Esther Boserup (1987), ao analisar a prática do pousio, indica que sua origem está relacionada à necessidade de minimização dos efeitos do crescimento populacional sobre os recursos naturais. Sem tomar como base os fatores ecológicos ou a capacidade adaptativa do homem, a autora defende que a pressão populacional per si é a causadora de mudanças das formas de cultivo e, consequentemente, do aparecimento das inovações, sem que necessariamente estejam ligadas à capacidade de inovação dos agricultores. O pousio é então uma resposta ao crescimento demográfico, e a adaptação de práticas ao ambiente natural representa para autora menos esforço de trabalho, diretamente relacionado ao número de membros existentes na unidade familiar (RAVENA, 2010). Entretanto, outros autores defendem o pousio como uma técnica criada em função da necessidade de manutenção da fertilidade do solo e, portanto, uma inovação que se adapta a partir das características ecológicas dos mais diversos ambientes amazônicos (FRAXE et al., 2011).

No PAE Botos não foi identificada a realização de pousio. No PDS Realidade 26,19\% dos agricultores realizam pousio por aproximadamente 2,25 anos, em média. Fraxe (2000) encontrou período de pousio de até 8 anos em comunidades de várzea do rio Solimões. Neste período, forma-se uma capoeira "madura" enriquecida com frutíferas após a eliminação da roça. Portanto, nem sempre as áreas deixadas em pousio são utilizadas novamente. As capoeiras enriquecidas com frutíferas podem tornar-se pequenos sítios, e as áreas mais distantes podem simplesmente ser abandonadas, originando a formação de uma floresta secundária.

Além do pousio, foram observadas importantes estratégias de manutenção do solo e dos plantios que podem ser reconhecidas como práticas agroecológicas (Quadro 1). Em sistemas familiares de produção é comum o uso de técnicas tradicionais de cultivo, tais como adubação orgânica, cultivos consorciados, adubação verde, sistemas agroflorestais, geralmente práticas pouco dependentes de insumos químicos e que aliam produção agrícola à conservação dos recursos naturais (CABRAL, 2010). Estas práticas vêm sendo estudadas pela ciência agroecológica para buscar formas de aliar suas vantagens ambientais ao retorno econômico, além de verificar a viabilidade de sua disseminação inclusive junto ao agronegócio, reduzindo assim a necessidade de modificações bruscas na base natural de recursos e consequentemente promovendo maior sustentabilidade na produção agrícola. A observação de práticas desta natureza é imprescindível em 
áreas destinadas ao uso sustentável, uma vez que poderá ampliar o conhecimento sobre a viabilidade de seu uso e aproveitar as práticas tradicionais de cultivo nos programas governamentais de desenvolvimento.

Quadro 1: Práticas agroecológicas utilizadas pelos agricultores na região estudada.

\begin{tabular}{|c|l|}
\hline Prática & \multicolumn{1}{c|}{ Tipo } \\
\hline \multirow{3}{*}{ Adubação orgânica } & \begin{tabular}{l}
\multicolumn{1}{c|}{ - Aplicação de restos de alimento ao redor do caule; } \\
- Amontoa de folhas secas ao redor do caule; \\
- Adubação com restos vegetais em decomposição; \\
- Utilização de esterco de galinha; \\
- Mistura resto de material vegetal decomposto com \\
terra preta e esterco bovino diretamente nas covas; \\
- Mistura material vegetal decomposto com palha de \\
arroz.
\end{tabular} \\
\hline Consorciamento & $\begin{array}{l}\text { - Banana, mandioca e açaí; } \\
\text { - Hortaliças, mandioca, milho, arroz e banana. }\end{array}$ \\
\hline Plantio direto & $\begin{array}{l}\text { Realiza limpeza da área manualmente, e abre as covas } \\
\text { para realizar o plantio das mudas. }\end{array}$ \\
\hline Controle alternativo de & $\begin{array}{l}\text { Retirada manual de partes vegetais com sintomas de } \\
\text { doenças e/ou ataque de pragas. }\end{array}$ \\
\hline pragas e doenças
\end{tabular}

Fonte: Pesquisa de campo (NUPEAS/UFAM e NUSEC/UFAM). Elaboração das autoras.

$\mathrm{Na}$ várzea, o uso de adubo orgânico é baixo, pois os agricultores afirmam que não há necessidade de adubar, já que a terra é naturalmente fértil. No PAE Botos, 10\% dos agricultores utilizam adubação orgânica e não foi citado o uso de adubo químico. Os adubos usados são produzidos pela mistura de terra queimada, material vegetal decomposto (principalmente folhas de castanheira e palha de arroz) e esterco bovino diretamente. No PDS Realidade, 30\% dos agricultores utilizam adubo químico como ureia e NPK, 30\% utilizam adubação orgânica a base de esterco, restos vegetais e terra preta, e 40\% não utilizam nenhum tipo de adubo.

Outro exemplo de prática que corrobora aos princípios da agroecologia é o uso de consorciamento entre espécies e a própria diversidade de sistemas utilizados para organização dos plantios: os quintais, os jiraus, os canteiros, a roça, as praias e a capoeira, localizados em áreas de várzea ou terra firme, formando muitas vezes pequenos sistemas agroflorestais (SAFs). O consorciamento consiste em intercalar diferentes espécies frutíferas e anuais em uma mesma área, e nos sistemas agroflorestais associados a estas, introduzem-se espécies florestais. Estes sistemas têm como vantagens uma produção mais estável, pelo incremento de mais 
fontes alimentares e de renda, maior eficiência no controle de pragas e doenças, proteção do solo contra processos erosivos, manutenção da água e nutrientes do solo e maximização da força de trabalho, pois, ao invés de controlar diversas áreas, o agricultor concentra os cultivos em uma área menor (EMBRAPA, 2006). No PAE Botos, os principais consorciamentos observados foram de mandioca (Manihot sp.) com banana (Musa sp.) e açaí (Euterpe sp.). No PDS Realidade, os principais consórcios observados são entre hortaliças, mandioca, milho (Zea mays), arroz (Oriza sativa) e banana.

Do ponto de vista técnico, as principais vantagens do consorciamento são: melhor aproveitamento da luz solar, aumento da produtividade sem elevação dos custos, maior eficiência do uso da terra e da mão de obra e diminuição dos riscos de perdas das culturas consorciadas em função do clima (PAULUS et al., 2000). Para o agricultor, representa a possibilidade de maior aproveitamento do espaço, já que estão em locais com restrições ao aumento da área de produção, além de mais uma oportunidade de diversificar as fontes de renda, pois utilizam espécies temporárias que possibilitam retorno econômico mais rapidamente, como, por exemplo, a banana e a mandioca e espécies perenes, que garantem o retorno econômico mais a longo prazo, porém, com espécies de boa aceitação no mercado local, como o açaí.

Amorozo (2002) afirma que a diversidade de espécies cultivadas nestes sistemas, além de ampliar a segurança alimentar das famílias, representa também uma importante fonte de material genético para o desenvolvimento de cultivos híbridos, espécies mais resistentes a pragas ou doenças e adaptadas às mudanças climáticas sofridas na região. Sua utilização tem sido incentivada ainda pelos benefícios à recuperação de áreas degradadas, pois a combinação de espécies animais e vegetais melhora as propriedades físico-químicas de solos degradados e aumenta a atividade microbiana, pela diversidade de fontes de matéria orgânica (REINERT, 1998; MENDONÇA et al., 2001 apud CASTRO et al., 2009).

Os sistemas agroflorestais (SAFs) foram incorporados por antigas culturas e disseminados por indígenas e caboclos por toda a Amazônia (DANIEL et al., 2000). Os SAFs são observados nas duas áreas estudadas neste trabalho, chamando atenção a sua presença no PDS Realidade, que não é constituído prioritariamente por comunidades tradicionais. Mesmo os agricultores oriundos de outras regiões do país, principalmente do Centro-Oeste e do Sudeste, praticantes do monocultivo em suas regiões de origem, adotaram os SAFs como sistema de cultivo. Este fato exemplifica a capacidade de adaptação dos camponeses a diferentes contextos sociais mediante a migração, modificando suas características iniciais de existência. 
Adicionalmente à ampliação das fontes de renda, os SAFs possibilitam ainda a conservação dos nutrientes naturais do solo e as condições físicas favoráveis ao desenvolvimento das plantas (ALVES; MODESTO JÚNIOR, 2012). Na região estudada, os SAFs são encontrados principalmente nos quintais, com a associação entre espécies frutíferas, hortaliças, espécies florestais como açaí, bacaba, pupunha, espécies medicinais, ornamentais e criação animal ao redor da casa. Além de minimizar o esforço físico do trabalho, proporciona o fornecimento de diversos bens e serviços produzidos pela própria família.

Além do consorciamento e dos SAFs como práticas agroecológicas, observase também um baixo uso de produtos fitossanitários (agrotóxicos), quando comparado com sistemas convencionais de cultivo. A maioria dos agricultores utilizam técnicas alternativas para o controle de pragas e doenças. No PAE Botos, para evitar o ataque de plantas invasoras, os agricultores realizam capinas manuais e acrescentam uma mistura de esterco bovino curtido com palha de arroz para afugentar formigas.

Diante das práticas apresentadas, observa-se que os agricultores são os principais experimentadores das práticas conservacionistas, buscando sempre adaptar sua realidade ao sucesso dos cultivos. Desta forma, é importante incluir o conhecimento local no desenvolvimento de técnicas de produção agrícola como uma forma de conhecimento válido, pois ajuda a construir e desenvolver a agricultura familiar, resgatando o saber do agricultor sobre o potencial agrícola de seu agroecossistema. Este conhecimento é usado para sustentar a comunidade, sua cultura e os recursos naturais necessários para a sobrevivência contínua das comunidades rurais (FRAXE, 2004).

\section{O IAD FRAMEWORK DAS RELAÇÕES INSTITUCIONAIS}

As relações institucionais são constituídas a partir de regras formais e informais entre os moradores dos assentamentos e instituições governamentais e não governamentais que atuam nas áreas. A análise destas relações é fundamental para compreensão do papel das instituições na regulação do uso comum na Amazônia, pois evidencia as oportunidades existentes para permanência e/ou melhoria de práticas de uso que atendam aos princípios da agroecologia.

As principais instituições presentes no PAE Botos são a "Associação de Desenvolvimento dos Trabalhadores Rurais do PAE Botos", formalizada em 2006, para representar os interesses dos moradores do assentamento; a diocese de Humaitá, que juntamente com ações de evangelização, auxilia na aproximação 
dos moradores com as instituições governamentais na solução de problemas relacionadas ao uso da terra; o Instituto Internacional de Educação do Brasil (IIEB) - instituição não governamental e o INCRA.

A partir da análise dos formulários aplicados e da coleta de dados nas reuniões participativas, foi possível identificar que a associação do PAE Botos encontra-se enfraquecida. Ocorre uma baixa participação dos moradores nas atividades coletivas, nas reuniões da associação e na frequência ao pagamento das mensalidades. Os moradores demonstram um baixo nível de emponderamento em relação à conscientização dos benefícios a serem alcançados caso estejam organizados coletivamente, já que a maioria dos associados participa apenas à base de incentivos materiais (VERDEJO, 2006). A associação apresenta dificuldades de gerenciamento, não estando apta para gerir os programas governamentais a serem implementados diante da perspectiva de elaboração do Plano de Uso da área.

Um dos exemplos do baixo nível de iniciativa da associação local é a falta de encaminhamentos para solucionar a principal causa de conflitos no assentamento: o uso dos castanhais. Existem conflitos entre pessoas que se apresentam como "donos" dos castanhais, portadores de títulos remanescentes da década de 1930, e os moradores extrativistas. O INCRA e as instituições atuantes na área ainda não conseguiram solucionar os confrontos ente "patrões"3 e extrativistas, que envolvem inclusive atos de violência física.

Desta forma, a associação do PAE Botos, que poderia ser a instituição mais próxima dos moradores, já que representa diretamente as demandas comunitárias, encontra-se entre as instituições mais distantes. Os moradores mostram-se insatisfeitos com a atuação da organização e não confiam na instituição para mediar a solução dos problemas enfrentados junto aos órgãos competentes.

Em relação ao PDS Realidade, as instituições mais próximas do assentamento são a Associação dos Produtores Rurais da Realidade (ASPRUR), fundada em 2006, e o INCRA. Semelhante ao PAE Botos, o PDS Realidade apresenta problemas relacionados à organização social. A principal dificuldade apontada pela associação é o acesso a recursos financeiros e/ou técnicos, devido às exigências burocráticas e à dificuldade de comunicação. Os recursos

\footnotetext{
O patrão é reconhecido como dono do castanhal. Empresta dinheiro ou produto aos moradores (produtores) em troca dos produtos oferecidos por estes ou mesmo paga em dinheiro pela compra dos produtos. A figura do patrão é remanescente do sistema de aviamento instalado na Amazônia no período áureo da borracha, e permanece até hoje no Amazonas como agente intermediador da comercialização. No caso do PAE Botos, os patrões eram reconhecidos como donos dos castanhais pelos extrativistas e essa hierarquia de poder era respeitada. Após a criação do assentamento, mediante a ausência do poder público para esclarecimento da legislação e estabelecimento de acordos, ou seja, empoderar (empowerment) os envolvidos às novas regras, o conflito se estabeleceu, uma vez que agora os moradores se recusam a dividir a produção com os patrões.
}

Novos Cadernos NAEA • v. 17 n. 1 • p. 99-124 • jun. 2014 
materiais são escassos e também é observada uma baixa capacidade gerencial. A associação não possui sede, materiais ou equipamentos de trabalho, sendo as reuniões realizadas em um barracão próximo à casa da liderança local.

São observadas divergências entre os associados que dificultam a mobilização dos moradores em torno de objetivos comuns. A principal causa dos desentendimentos foi atribuída pelos moradores à existência de dois núcleos populacionais: antigos e novos moradores. Mesmo após a criação do assentamento ocorre a invasão de terras por posseiros, intensificando problemas de furto e, consequentemente, conflitos entre as comunidades. A submissão de regras diferenciadas daquelas demandadas pelos moradores ${ }^{4}$ culminou em conflitos no local e no descontentamento das famílias em relação ao órgão gestor. Como consequência, permanece a venda de lotes, favorecendo o processo de grilagem e a venda ilegal de madeira.

Um fator comum observado nas duas áreas é a percepção dos moradores quanto à distância do INCRA (órgão gestor) em relação às comunidades. Cerca de 53,03\% dos moradores mostram-se insatisfeitos com a atuação do órgão, considerando que os recursos e direitos disponibilizados têm sido inacessíveis e insuficientes. Além disso, 47,33\% dos entrevistados classificaram a relação com o INCRA como ruim.

\section{CONCLUSÕES}

As políticas ambiental e agrária, por pressuporem na base legislativa fundamentos alheios à realidade institucional da Amazônia, limitam o fortalecimento dos arranjos institucionais e a consolidação de suas relações. As dificuldades apresentadas em torno da organização social e as relações institucionais enfraquecidas culminam na vulnerabilidade da permanência de práticas agroecológicas de uso dos recursos naturais nos assentamentos.

O uso da terra em Assentamentos Agroextrativistas e Assentamentos de Desenvolvimento Sustentável é definido mediante a "concessão de uso, em regime comunal, segundo a forma decidida pelas comunidades concessio-

4 Ao solicitar a criação do assentamento ao INCRA, os moradores objetivavam a definição dos lotes e o recebimento do documento de propriedade, ou seja, a criação de um assentamento na modalidade PA. Entretanto, foi criada a modalidade PDS, e esta não permite a demarcação de propriedades individuais, tendo o morador que se adaptar ao "uso comum". Este fato também tem culminado em conflitos no local, seja pelo desconhecimento dos moradores em relação aos critérios de uso dos recursos da área (o que é uso comum?), seja pela falta de orientação do INCRA na apropriação dos moradores a esta nova realidade. 
nárias - associativista, condominial ou cooperativista" (Portaria INCRA nº 268, de 1996). Entretanto, os moradores não foram apropriados dos princípios deste sistema, e os dispositivos estabelecidos pela lei ao invés de amenizar os conflitos em torno do uso dos recursos, contribuem para acirrar os desentendimentos entre os moradores.

Outro problema que prejudica a permanência das práticas agroecológicas de baixo impacto ao ambiente, e que gere melhorias socioeconômicas aos moradores é a insuficiência da assistência técnica. Para que a produção seja organizada, no sentido de maximizar o uso potencial da área, conciliado à sustentabilidade dos recursos, a orientação técnica é importante, principalmente diante das restrições de uso às quais os assentamentos estão submetidos, ou seja, a área dos roçados é limitada e o uso dos recursos como fonte de renda deve ser planejado de forma comunitária.

Desde a criação dos assentamentos, o INCRA não disponibilizou técnicos para acompanhamento das atividades socioeconômicas e o Instituto de Desenvolvimento Agropecuário e Florestal Sustentável do Estado do Amazonas - IDAM, órgão responsável pela assistência técnica nas atividades agroflorestais do Estado não tem regularidade de visita ao local, sendo a média de uma vez ao ano.

As formas de produzir organizadas a partir dos conhecimentos tradicionais adquiridos na prática e repassados entre as gerações, com incorporações constantes de inovações tecnológicas, tornam-se vulneráveis à adoção de práticas convencionais (utilizadoras de insumos industriais). A insuficiência do acompanhamento técnico por parte do órgão gestor e a influência negativa das pressões de mercado incentivam o uso da queima no preparo dos roçados e uso de produtos fitossanitários (agrotóxicos).

Entretanto, em meio à instabilidade proporcionada pelo ambiente físico e pelas relações institucionais enfraquecidas, os moradores atuam a partir de escolhas que lhes propocionam uma relativa estabilidade. É observada uma continuidade das inovações tecnológicas de base agroecológica, criadas mediante as necessidades das famílias, e sua experimentação empírica. Estas arenas de ação resultam, portanto, na adoção de práticas menos nocivas à conservação da base material de recursos, uma vez que deles dependem a manutenção e a permanência deste modo de vida. 


\section{REFERÊNCIAS}

ADAMS, C. As populações Caiçaras e o Mito do Bom Selvagem: a necessidade de uma nova abordagem interdisciplinar. Revista de Antropologia, v. 43, n. 19, 2000 .

ALMEIDA, A. W. B. Conflitos sociais no Complexo Madeira. Projeto Nova Cartografia Social da Amazônia. Manaus: UEA, 2009.

ALVES, R. N. B.; MODESTO JÚNIOR, M. S. Roça sem fogo e trio da produtividade da mandioca. Inclusão Social, v. 6, n. 1, 2012.

AMOROZO, M. C. M. Uso e diversidade de plantas medicinais em Santo Antônio do Leverger, MT, Brasil. Acta Bot. Bras., v. 16, n. 2, p.189-203, 2002.

BELlO, O. C.; COSTA, F. S. Organização produtiva no Projeto de Desenvolvimento Sustentável Realidade no município de Humaitá-AM. 2011. Trabalho de Conclusão de Curso (Graduação). Universidade Federal do Amazonas, Humaitá, 2011.

BOSERUP, E. Evolução agrária e pressão demográfica. São Paulo: Hucitec, 1987.

BRANCO, F. M. C. As relações de trabalho na pequena produção da várzea no Estado do Amazonas. 1993. Trabalho de Conclusão de Curso (Graduação) - Universidade Federal do Amazonas, Manaus, 1993.

BRASIL. Instituto Nacional de Colonização e Reforma Agrária. Relatório de Atividades. Humaitá: INCRA, 2011.

BRASIL. Publicação especial do Instituto Nacional de Colonização e Reforma Agrária. Jornal do INCRA, dez., 2010.

BRESSER-PEREIRA, L. C. Instituições, bom estado, e reforma da gestão pública. In: BIDERMAN, C.; ARVATE, P. (Orgs.). Economia do Setor Público no Brasil. São Paulo: Campus; Elsevier, 2004. P. 3-15.

CABRAL, W. S. Impacto e viabilidade do uso de manejo conservacionistas na agricultura familiar no entorno do açude Epitácio Pessoa. 2010. Dissertação (Mestrado) - Universidade Federal de Campina Grande, Campina Grande, 2010.

CAPORAL, F. R.; COSTABEBER, J. A. Agroecologia e desenvolvimento rural sustentável: perspectivas para uma extensão rural. In: Agroecologia e Desenvolvimento Rural Sustentável, v.1, n.1, p. 16-37, jan./mar., 2004. 
CASTRO, A. P.; FRAXE, T. J. P.; SANTIAGO, J. L.; MATOS, R. B.; PINTO, I. C. Os sistemas agroflorestais como alternativa de sustentabilidade em ecossistemas de várzea no Amazonas. Acta Amazonica, v. 39, n. 2, 2009, p. 279-288.

CONCEIÇÃO, O. A. C. O conceito de instituição nas modernas abordagens institucionalistas. R. Econ. contemp., Rio de Janeiro, v. 6, n. 2, p. 119-146, jul./ dez. 2002.

DANIEL, O.; PASSOS, C. A. M.; COUT, L. Sistemas agroflorestais silvipastoris e agrissilvipastoris na região Centro-Oeste do Brasil: potencialidades, estado atual da pesquisa e da adoção de tecnologia. In: SIMPÓSIO INTERNACIONAL SOBRE SISTEMAS AGROFLORESTAIS PECUÁRIOS NA AMÉRICA DO SUL. 2000. Juiz de Fora. Anais... Juiz de Fora, 2000.

DIEGUES, A. C. O mito Moderno da Natureza intocada. 4. ed. São Paulo: Annablume; Hucitec; NUPAUB/USP, 2002.

EMBRAPA. Sistemas de Produção, 13. Versão Eletrônica, dez./2006. Disponível em: < http://sistemasdeproducao.cnptia.embrapa.br/FontesHTML/ Vinagre/SistemaProducaoVinagre/custo.htm>. Acesso em: 8 nov. 2013.

FLECK, L. C. Eficiência econômica, riscos e custos ambientais da reconstrução da rodovia BR-319. Conservação Estratégica. Lagoa Santa, 2009. 88 p. (Série Técnica, n. 17).

FRAXE, T. J. P. Homens anfíbios: etnografia de um campesinato das águas. São Paulo: Anablume; Fortaleza: Secretaria da Cultura e Desporto do Governo do Estado do Ceará, 2000.

FRAXE, T. J. P. O saber local e os agentes da comercialização na Costa da Terra Nova, no Careiro da Várzea. In: ENCONTRO ANPPAS, 2. 2004. São Paulo. Anais... São Paulo, 2004.

FRAXE, T. J. P.; WITKOSKI, A. C.; PEREIRA, H. S. Amazônia: cultura material e imaterial. São Paulo: Annablume, 2011. v. 1. 372p.

HARDIN, G. Tragedy of commons. Science, n. 162, p. 1243-48, 1968.

HODGSON, G. M. What are Institutions? Jounal of Economics Issues. v. XL, n. 1, Mar. 2006.

IIEB-Instituto Internacional de Educação do Brasil. Relatório de Atividades. Humaitá: IIEB, 2008. 
IIEB-Instituto Internacional de Educação do Brasil. Relatório de Atividades. Humaitá: IIEB, 2010.

OLSON, M. A Lógica da Ação Coletiva. São Paulo: EDUSP, 1999.

OSTROM, E. Governing the Commons: the evolution for collective action. Cambridge: University Press, 1990.

OSTROM, E. Understanding Institutional Diversity. Princenton: University Press, 2005.

OSTROM, E.; GARDNER, R.; WALKER, J. Rules, games \& common-pool resources. Ann Arbor: University of Michigan Press, 1994.

PAULUS, G.; MÜLLER, A. M.; BARCELLOS, L. A. R. Agroecologia aplicada: práticas e métodos para uma agricultura de base ecológica. Porto Alegre: EMATER, 2000.

RAVENA, N. Ecologia política e estratégias de sustentabilidade: uma reflexão teórica. Novos Cadernos NAEA, v. 13, n. 2, p. 103-120, dez. 2010.

RAWLS, J. Uma Teoria da Justiça. São Paulo: Martins Fontes, 2000a.

REINERT, D. J. Recuperação de solos em sistemas agropastoris. In: Recuperação de Áreas Degradadas. Viçosa: UFV, 1998. p. 163-176.

REPLOGE, R. Recovering the Social Contract. Totowa: Rowman \& Littlefield, 1989.

SCHNEIDER, S.; SCHIMITT, C. J. O uso do método comparativo nas Ciências Sociais. Cadernos de Sociologia, Porto Alegre, v. 9, p. 49-87, 1998.

SOUZA, J. L. Agricultura Orgânica: tecnologias para a produção de alimentos saudáveis. Vitória: Incaper, 2005. 2v. 257p.

VERDEJO, M. Diagnóstico Rural Participativo: um guia prático. Brasília: [s.n.], 2006. 
